\title{
Differences in frequency of finger tremor in otherwise asymptomatic mercury workers
}

\author{
Larry J Chapman, Steven L Sauter, Robert A Henning, Vernon N Dodson, William G Reddan, \\ Charles G Matthews
}

\begin{abstract}
Tremor was measured from the index finger during low force, position holding in 18 control subjects and 18 battery workers with low level exposure to mercury. All workers were asymptomatic on clinical neurological examination. No differences were found in average tremor amplitudes between the groups, but statistically significant abnormalities in tremor frequency distribution existed. Tremor power spectra in the group of mercury workers were shifted toward the higher frequencies and compressed into narrow frequency peaks. These results suggest that measurements of finger tremor that evaluate the frequency distribution can produce a higher diagnostic yield than traditional visual clinical judgement. The findings also confirm other reports that currently permitted exposures to mercury are associated with subtle but distinctive differences in tremor accompanying voluntary movement.
\end{abstract}

Evidence has accumulated that subtle neurological changes can accompany low level exposures to occupational mercury near or below permitted limits (U.S. Occupational Safety and Health Administration inorganic mercury standard, eight hour time weighted average $=0.1 \mathrm{mg} / \mathrm{m}^{3}$ air). Studies of asymptomatic mercury workers with normal clinical neurological examinations have detected deficits in memory and vigilance, ${ }^{1-4}$ emotional function, ${ }^{5-7}$ tactile sensation at extremities, ${ }^{89}$ and in psychomotor co-ordination. ${ }^{1271011}$ Also, some studies of asymptomatic workers have reported on physiological tremor, an objective, involuntary end point of motor control. ${ }^{10-16}$ Some of these studies examined the frequency spectrum of limb micromovements and identified distinctive changes in upper extremity tremor including peaks and upward shifting in the power distribution. ${ }^{11}$ Frequency analysis of finger

Departments of Neurology and Preventive Medicine, University of Wisconsin, Madison, Wisconsin, USA

L J Chapman, S L Sauter, R A Henning, V N Dodson, W G Reddan, C G Matthews force tremor is gaining scientific attention as a promising indicator of overall motor unit activity that can provide insight into the two neural mechanisms that control production of muscle forcenamely, recruitment and modulation of firing rate. This information is useful for pathophysiological and diagnostic purposes, and is not available with current electromyographic or microneurographic techniques. ${ }^{17}$

We used a measurement system specifically designed to be sensitive to subtle amplitude and frequency features by being sufficiently lightweight and pliable to accurately track fine vertical movement oscillations. Subjects were positioned so that tremor was measured from the isolated index finger of the supported hand, a low mass limb segment less likely to damp oscillations, and with less intersubject anthropometric variability in size, weight, and elasticity than the extended hand, forearm, or entire upper extremity. ${ }^{18}{ }^{19}$ The natural resonant frequency of the index finger has been determined to be around $25 \mathrm{~Hz}$, well outside the range of the neuromuscular frequencies of interest in tremor measurement (4-16 $\mathrm{Hz})^{20}$

We evaluated finger tremor associated with precision movement in a group of 18 asymptomatic mercury workers and age matched controls. All the mercury workers received a special medical examination specifically designed to search for signs and symptoms of mercury toxicity. Urine samples of workers were also evaluated for mercury content. The purpose of the investigation was to compare the sensitivity and specificity of tremor measurement to conventional clinical examination procedures. We were also interested in determining whether certain features of tremor frequency were shared by the mercury workers and how they were related to indicators of exposure.

\section{Methods}

SUBJECTS

The 18 study subjects were employed by one firm and worked in one of three plants producing cylindrical, alkaline magnesium batteries and button type mercury battery cells. Their mean age was 33.3 (SD $12 \cdot 6$, range $20-57$ years). Fourteen were men and four were women. The mean duration of exposure 
was $5 \cdot 3$ years (SD $7 \cdot 5$, range $0 \cdot 3-32$ ). Half the group had worked for two years or less. Three subjects were newly hired and had been exposed for less than six months. All the employees were exposed to elemental mercury and inorganic mercury compounds that were amalgamated with zinc and used to prevent corrosion in both types of battery products. All clinical examinations and tremor assessments took place during weeks in which workers experienced actual, ongoing exposures. The exposed group was drawn from a number of different job classifications and all spent time on the production line.

The control group comprised 18 healthy, unexposed subjects selected by age from a larger group of 27 normal people who underwent tremor assessment. Their mean age was $36 \cdot 6$ (SD $11 \cdot 4$, range 1951 years). Six were men and 12 were women. The mean educational level of the controls (13.2 years) was somewhat higher than that of the mercury workers $(12 \cdot 6)$. There is no evidence to suggest that physiological finger tremor is influenced by sex or educational attainment. The study protocol was approved by the university human subjects committee, and subjects gave informed consent.

\section{SCREENING QUESTIONNAIRE}

Exposed and control subjects were carefully screened with a specially designed questionnaire and a guided health history interview that searched for signs of mercury toxicity. Each person was questioned about age, alcohol and drug use, health history and current health state, work history, and current job characteristics, as well as previous conditions or agents with neuropathic potential. Grounds for exclusion included previous or current injuries or illnesses with neuropathic potential, and exposures to neurotoxic drugs or chemicals.

\section{PHYSICAL AND NEUROLOGICAL EXAMINATIONS}

The mercury workers were evaluated by a board certified occupational medicine physician who carried out a specially designed examination that searched for the range of symptoms (gum tenderness, metallic taste, increased salivation, teeth loosening, personality change, tremors, difficulty with writing, increased perspiration, appetite loss) and signs (gingivitis, gum discoloration, eyelid tremor) associated with mercury toxicity. Standard neurological tests of postural steadiness, gait, and finger tremor on voluntary movement were also included, as well as visual assessment of extended index finger tremor at rest with the hand supported. At least one measure of mercury concentration in urine was obtained for each worker from a 24 hour sample obtained the day before administration of the questionnaire, clinical examination, and tremor assessment session. Concentrations of mercury in urine were not assessed in the control group.

\section{MOVEMENT TESTING}

Tremor testing was carried out in a controlled humidity and temperature setting. It took place with subjects seated comfortably in a chair with their dominant arm resting on a table surface located slightly below elbow height. Subjects assumed a closed fist, pronated arm pose with the index finger extended. The subject's arm, wrist, and hand were firmly supported so that movement about the metacarpophalangeal joint of the index finger was isolated (fig 1). This protocol for measurement of finger

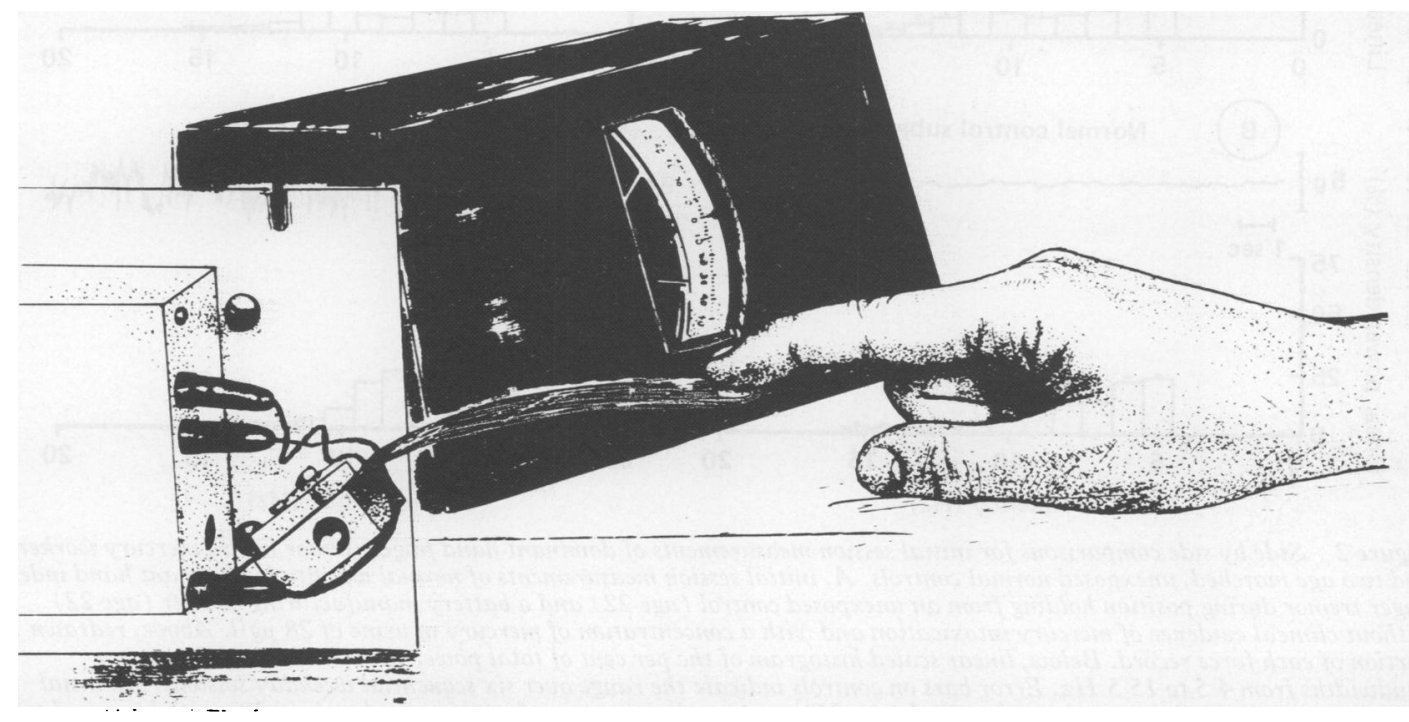

Figure 1 Tremor transducer instrument in use. 
tremor is consistent with that used in other investigations. ${ }^{16-19}$ Subjects depressed a spring bronze transducer arm with the index finger of their dominant hand. Voluntary regulation of the stationary downward force exerted by the subject on the flex strip ( $5 \mathrm{~g}$ ) was assisted by an analogue, position feedback display located next to the transducer. Subjects were instructed to maintain a steady force for $60 \mathrm{~s}$ by keeping the display's pointer positioned within a designated range. To hold a steady position, subjects needed to correct for normal drift up or down. The position holding corrective adjustments were typically slow $(<4 \mathrm{~Hz})$ small finger extension or flexion movements in the vertical plane (5-20 $\mathrm{mm}$ ). The signals were fed into a minicomputer for power and frequency analysis. Spectral analysis software was utilised for the frequency analysis (Laboratory Subroutines Package, Digital Equipment Corporation). High sampling rates $(256 \mathrm{~Hz})$ and presample, low pass filtering $(30 \mathrm{~Hz}$ and $24 \mathrm{~dB}$ per octave) were used to control for frequency aliasing. A high pass filter $(3 \mathrm{~Hz}$ and $12 \mathrm{~dB}$ per octave) was used to remove artifacts due to voluntary movements at lower frequencies. ${ }^{21} 22$

\section{STATISTICS}

Group mean scores on four tremor parameters (amplitude, total power, half power frequency, and highest band power) were compared using the nonparametric Mann-Whitney test and considering the small group sizes and potential for non-normal and unequal variance distributions (see table for a definition of the tremor parameters). Multivariate discriminant analysis was used to determine which tremor parameters were most useful in distinguishing the mercury workers from normal subjects. The discriminant analysis utilised a total of 15 variables from each group; the four tremor parameters used in the Mann-Whitney test and 11 tremor per cent power values (at $1 \mathrm{~Hz}$ bandwidths from 4.5$15 \cdot 5 \mathrm{~Hz})$.

\section{Results}

All workers in the study group were judged asymptomatic after the interviews and clinical examinations. Mean concentration of mercury in urine for the battery worker group was 23.1 (SD 28.3) $\mu \mathrm{g} / 1$ and ranged from a high value of $121 \mu \mathrm{g} / 1$ in one employee to normal concentrations for eight battery workers,
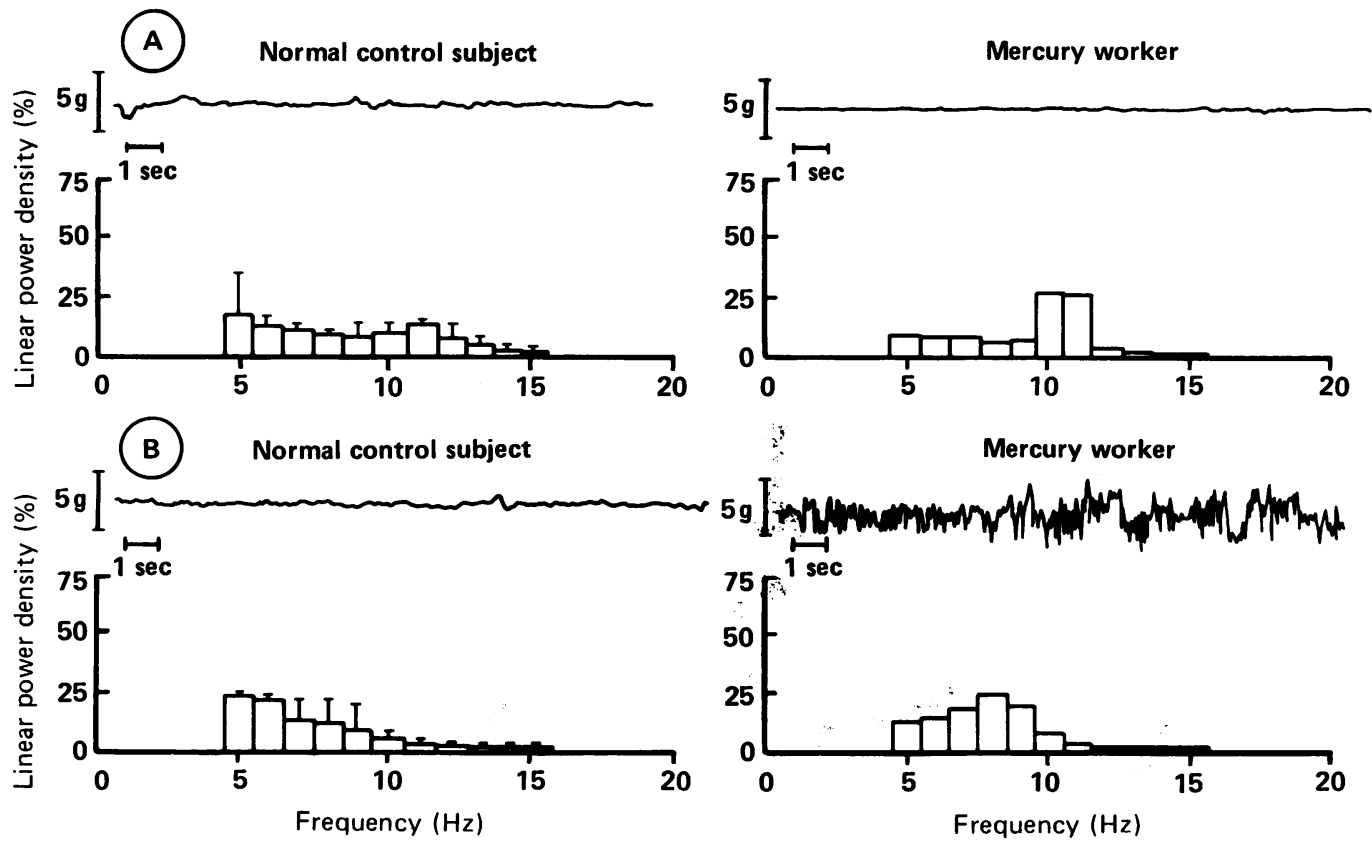

Figure 2 Side by side comparisons for initial session measurements of dominant hand finger tremor in two mercury workers and two age matched, unexposed normal controls. A, initial session measurements of normal amplitude dominant hand index finger tremor during position holding from an unexposed control (age 22) and a battery manufacturing worker (age 22) without clinical evidence of mercury intoxication and with a concentration of mercury in urine of $28 \mu g / l$. Above, redrawn $12 \mathrm{~s}$ portion of each force record. Below, linear scaled histogram of the per cent of total power in each of the 11 frequency bandwidths from 4.5 to $15.5 \mathrm{~Hz}$. Error bars on controls indicate the range over six sequential weekday sessions. B, initial session measurements in an unexposed control (age 36), and in a battery manufacturing worker (age 38) with increased tremor amplitude but without clinical evidence of mercury intoxication and with a concentration of mercury in urine of $51 \mu \mathrm{g} / \mathrm{l}$. 
of less than $10 \mu \mathrm{g} / \mathrm{l}$, figures comparable with those routinely found in unexposed controls in other studies. ${ }^{23}$

Examination of 13 of the 18 finger tremor frequency distributions in mercury workers showed a visually detectable peak and general upward shift in the distribution of spectral power relative to the records from controls. These abnormalities varied, however, greatly in magnitude and position on the frequency scale for each mercury worker. Figure 2 gives a side by side comparison of tremor from two mercury workers and age matched controls. Panel A depicts an unexposed control, and a mercuryexposed worker, who was employed as a cell analysis technician with a total work career of 21 months. In the battery worker, amplitude was normal but the tremor frequency distribution was abnormally shifted into the $10-15 \mathrm{~Hz}$ range. Panel $B$ depicts the results for an unexposed control and exposed battery worker employed as a quality control engineer with a total work career of 10 years. This mercury worker had a higher than normal amplitude during measurement of finger tremor that was not evident visually during clinical examination. An upward shift in the distribution of tremor spectral power was also evident in the mercury worker, but into the $5-9 \mathrm{~Hz}$ range. Seven other exposed employees had detectable peaks in the 5-9 $\mathrm{Hz}$ range and four others had peaks in the $10-15 \mathrm{~Hz}$ range.

Figure 3 shows distributions of group mean tremor frequency for the mercury workers and the controls. The group average percentages of total power were not significantly different at any of the $111 \mathrm{~Hz}$ frequency bands. The table shows Mann-Whitney test comparisons of group means for derived tremor parameters. Frequency differences in total power and highest band power occurred, but no differences in amplitude were found. A discriminant analysis generated by the Wilk's lambda method explained $50 \%$ of the variance in the selected values for tremor

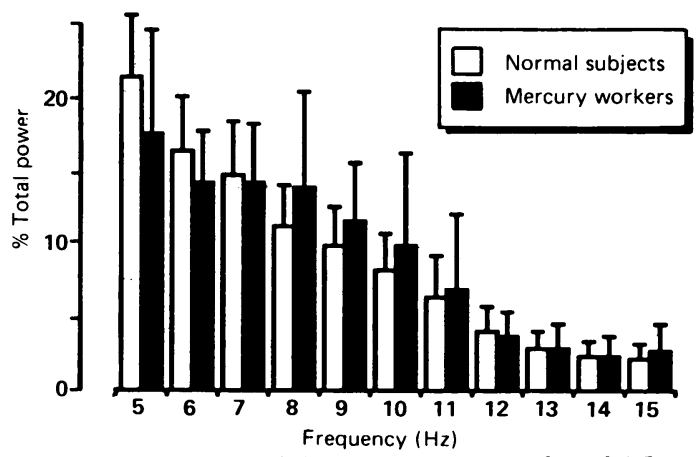

Figure 3 Histogram of the average per cent of total 4.5 to $15 \cdot 5 \mathrm{~Hz}$ power by frequency for dominant hand finger tremor measurements from group of mercury workers (black bars) and controls (white bars).
Tremor measurements in normal subjects and mercury workers

\begin{tabular}{lrrrrr}
\hline & \multicolumn{2}{c}{$\begin{array}{l}\text { Normal subjects } \\
(n=18)\end{array}$} & & \multicolumn{2}{c}{$\begin{array}{l}\text { Mercury workers } \\
(n=18)\end{array}$} \\
\cline { 2 - 3 } Variables & Mean & $S D$ & & Mean & $S D$ \\
\hline Amplitude ${ }^{\dagger}$ & 23.0 & 6.5 & & 35.6 & 2.5 \\
Total power + & 68.0 & 5.0 & & 315.0 & $37.0^{\star}$ \\
Half power frequency $\$$ & 7.5 & 0.6 & & 7.8 & 0.9 \\
Highest band power & 1.5 & 0.6 & & 2.6 & $2.3^{\star \star}$
\end{tabular}

${ }^{\star} \mathrm{p}<0.01 ;{ }^{\star \star} \mathrm{p}<0.001$, using Mann-Whitney test statistic adjusted for four comparisons.

$\dagger$ The average amplitude of the finger forces over a $60 \mathrm{~s}$ recording period was represented by the variance of the voltage values of the individual digitised values of the signal. Scale is linear and units are arbitrary.

+ The spectral power values at all frequencies from 4.5 to $15.5 \mathrm{~Hz}$ were summed to obtain total tremor power expressed here in arbitrary units and linear scale.

$\$$ The half power frequency was defined as that frequency value in $\mathrm{Hz}$ that evenly divided the power in the spectrum $\left(50^{\circ}{ }_{0}\right.$ of the total spectral power above and $50^{\circ}{ }^{\circ}$, below this frequency value).

The average power across the $5-15 \mathrm{~Hz}$ spectrum for the entire control group was subtracted from each individual spectrum. The $1 \mathrm{~Hz}$ bandwidth that deviated the most from the control group average was designated the highest bandwidth power deviation and was specified in standard deviation units from the normal group average (absolute values)

parameters. The discriminant function ranked the quantitative tremor parameters in the following order of importance: highest band power, amplitude, $15 \mathrm{~Hz}$ power, and $8 \mathrm{~Hz}$ power. This discriminant analysis correctly classified 14 of the 18 battery workers ( $72 \%$ correct) and misclassified one control (94\% correct for control group classification and $83 \%$ correct overall for both groups).

Examinations of scatterplots and correlation coefficients failed to disclose any clear relation between urine mercury concentrations or exposure types or durations and the magnitude of tremor parameter differences within the group of mercury workers.

\section{Discussion}

Exposures to mercury were associated with abnormal features in measurements of tremor compared with an age matched control group. The mercury exposed group, however, did not exhibit symptoms or clinical signs during a focused clinical examination. Significant differences were present in parameters derived from group average tremor frequency spectra but not in amplitude. A multivariate discriminant function analysis was able to successfully classify $72^{\prime \prime}$ " of the asymptomatic mercury workers on the basis of their tremor measurements and misclassified only one control.

Distributions in tremor energy were compressed into peaks in 13 of 18 exposed workers and shifted toward the upper bounds of the spectrum for finger tremor. Increased power and upward shifting have been consistently observed in previous measurements of mercury tremor, although the research 
protocols differed between laboratories with regard to exposures, body segment recorded from, limb positioning, limb loading and transduction, and analytical methods. ${ }^{101114162425}$ Such upward shifting of tremor energy has also been observed in myopathies and certain types of peripheral neuropathy. ${ }^{26}{ }^{27}$

In some of the previous work on low level exposure to mercury, simple amplitude measures were significantly increased above normal. ${ }^{1124}$ We did not observe significant group mean amplitude differences in these workers manufacturing batteries, perhaps in part due to the low mercury concentrations in urine relative to other studies, and the lack of any manifest symptoms in the present group. Significant differences in tremor frequency were present in the mercury workers evaluated here despite a smaller group size $(n=18)$ and a lower average mercury concentration in urine $(23 \mu \mathrm{g} / \mathrm{l})$ than in other studies detecting tremor differences. ${ }^{10112528}$ Single 24 hour concentrations of mercury in urine were within the range considered normal for unexposed persons in eight of the 18 clinically asymptomatic workers we studied.

Neither duration of working career nor 24 hour concentrations of mercury in urine were related to tremor changes. This may have resulted because we did not use creatinine standardised analyses to correct for variability in urine dilution, or because we collected only single day urine samples, and not cumulated measures over longer periods. Even when such refinements have been employed in other studies, however, urine and blood based indicators of mercury exposure have often proved inadequate for establishing dose response gradients..$^{2-429-38}$

Currently, measurements of concentrations of mercury in workplace air and in blood and urine of employees are the principal indicators monitored to prevent toxicity. Mercury concentrations in blood and urine do not appear to be related in any simple way, however, to either traditional workplace air or indicators of work exposure, or to changes in health. Instances of low or normal biological mercury concentrations co-existing with pronounced intoxication are well documented, as are high concentrations in the absence of symptoms ${ }^{29}$ Concentrations in blood or urine have been shown to be insensitive to high mercury concentrations at small volume sites such as the brain. ${ }^{230}$ Mercury half life in the brain may exceed one year and considerable amounts have been detected at necropsies as much as 10 years after last exposure and after overt symptoms had faded before death. ${ }^{15031}$ Mercury concentrations in body fluid have commonly failed to relate well to neural outcome measures including clinical neurological findings, ${ }^{3233}$ electrophysiological measures, ${ }^{44}$ and neurobehavioural tests. ${ }^{3435} 36$

Two studies on mercury workers have suggested that different people encountering similar exposures, as indicated by the traditional exposure measures of air concentrations and durations of exposure, may show great variability in both actual absorption of mercury and in changes in health. ${ }^{11}{ }^{37}$ Prospective studies that pretested potential employees and then monitored changes over time have shown that young mercury workers with relatively short, low exposure work histories can manifest the greatest body fluid concentrations and changes in health. ${ }^{38}$ To explain these findings, researchers have hypothesised that effects of mercury toxicity may develop earlier than previously thought, and that differential susceptibility and selection may operate even during initial months of employment, forcing severely affected, often younger people, to leave the work. ${ }^{38}$ One conclusion from this research is that direct measurement of health outcomes such as tremor may provide a better indicator for preventing adverse exposures to mercury than either clinical examinations or monitoring concentrations of mercury in urine, blood, or workplace air.

It is not clear whether the tremor differences we found that were associated with exposures to mercury can persist or are likely to deteriorate with continued ageing or continued exposure, or both. In two reports, detectable changes in tremor parameters induced by mercury at subclinical exposure concentrations appeared to be entirely reversible after reductions in mercury body burdens in the study groups. ${ }^{1011}$ Other reports on occupational mercury intoxications have, however, observed more permanent alterations. ${ }^{153940} \mathrm{~A}$ recent follow up study of mercury refinery workers performed 10 years after overt intoxications noted that pronounced finger tremor remained visually apparent in 31 out of 70 subjects. In the affected refinery workers, tremor persisted even in employees who had been removed from exposure for many years and despite the fact that all other sequelae, including ataxia, incoordination, dizziness, insomnia, and fatigue, were long resolved. ${ }^{39}$ We have in preparation a case report on a battery worker with severe poisoning (requiring a stay in hospital of nine months) that also provides evidence that mercury induced tremor can persist. At discharge, our patient's mercury body burden indices were reduced and other neurological abnormalities were long resolved, with the exception of visually noticeable tremor.

The present findings of changes in tremor in an otherwise healthy mercury exposed occupational group suggest that measurement of tremor may provide a more sensitive means of detecting responses to mercury exposure than current methods that use clinical examination. Even when finger tremor appears to be visibly normal to the affected subjects and to observers, abnormalities of frequency can be present. With further research to substantiate the present results and determine the time course of 
changes in carefully monitored exposed groups, we believe measurement of tremor could become an extremely useful adjunct to current clinical and biological monitoring techniques in preventing mercury toxicity.

One of us (SLS) is now at the United States National Institute for Occupational Safety and Health (NIOSH), Cincinnati. Views expressed do not necessarily reflect those of NIOSH.

Requests for reprints to: Larry J Chapman, University of Wisconsin Neurology Department, $600 \mathrm{High}$ land Avenue, Madison WI, USA 53792.

1 Smith P, Langolf G. The use of Sternberg's memory scanning paradigm in assessing effects of chemical exposure. Hum Factors 1981;23:701-8.

2 Williamson A, Teo R, Sanderson T. Occupational mercury exposure and its consequences for behavior. Int Arch Occup Environ Health 1982;50:273-86.

3 Piikivi L, Hanninen H, Martelin T, Matere P. Psychological performance and long-term exposure to mercury vapors. Scand J Work Environ Health 1984;10:35-41.

4 Triebig G, Schaller K. Neurotoxic effects in mercury-exposed workers. Neurobehavioural Toxicology and Teratology 1982;4: 717-20.

5 Shapiro I, Sumner A, Spitz L, et al. Neurophysiological and neuropsychological function in mercury-exposed dentists. Lancet 1982;i:1147-50.

6 Forzi M, Cassitto M, Bulgheroni C, Foa V. Psychological measures in workers occupationally exposed to mercury vapors: a validation study. In: Horvath M, ed. Adverse effects of environmental chemicals and psychotropic drugs. Amsterdam: Elsevier, 1976.

7 Camerino D, Cassitto M, Desideri E, Angotzi G. Behavior of some psychological parameters in a population of a $\mathrm{Hg}$ extraction plant. Clinical Toxicology 1981;18:1299-309.

8 Albers J, Cavender D, Levine S, Langolf G. Asymptomatic sensorimotor polyneuropathy in workers exposed to elemental mercury. Neurology 1982;32:1168-74.

9 Vroom F, Greer M. Mercury vapor intoxication. Brain 1972;95: 305-18.

10 Miller J, Chaffin D, Smith R. Subclinical psychomotor and neuromuscular changes in workers exposed to inorganic mercury. Am Ind Hyg Assoc $J$ 1976;10:725-733.

11 Langolf G, Chaffin D, Henderson R, Tuttle H. Evaluation of workers exposed to elemental mercury using quantitative tests of tremor and neuromuscular functions. Am Ind Hyg Assoc J 1978;39:976-84

12 Verberk MM, Salle HJA, Kemper $\mathrm{CH}$. Tremor in workers with low exposure to metallic mercury. Am Ind Hyg Assoc J 1986;47:559-62.

13 Roels H, Gennart J, Lauwerys R, et al. Surveillance of workers exposed to mercury vapor. Am J Ind Med 1985;7:45-71.

14 Fawer R, DeRibaupierre Y, Guillemin M, Berode M, Lob M. Measurement of hand tremor induced by industrial exposure to metallic mercury. $B r J$ Ind Med 1983;40:204-8.

15 Suzuki T. Dose-response relationships of mercurials. In: Nriagu $\mathrm{J}$, ed. The biogeochemistry of mercury in the environment. Amsterdam: Elsevier, 1979.

16 Wood R, Weiss A, Weiss B. Hand tremor induced by industrial exposure to organic mercury. Arch Environ Health 1973;26: $249-52$.
17 Homberg V, Reiners K, Hefter H, Freund H. The muscle activity spectrum: spectral analysis of muscle force as an estimator of overall motor unit activity. Electroencephalogr Clin Neurophysiol 1986;63:209-22.

18 Wade $P$, Gresty $M$, Findley $L$. A normative study of postural tremor of the hand. Arch Neurol 1982;39:358-62.

19 Elble R, Randall J. Motor unit activity responsible for 8-12 Hz component of human physiological tremor. J Nexrophysiol 1976;28:370-83.

20 Marsden CD. Origins of normal and pathological tremor. In: Findley LJ, Capildeo R, eds. Movement disorders: tremor. New York: Oxford University Press, 1984:3-13.

21 Barber N. Experimental correlegrams and Fourier transforms. London: Pergamon, 1961.

22 Miall RC, Weir DJ, Stein JF. Visuomotor tracking with delayed visual feedback. Neuroscience $1985 ; 16: 511-20$.

23 Zielhuis RL. Health effects of trace metals. In: DiFerrante E, ed. Trace metals: exposure and health effects. New York: Pergamon, 1979:239-47.

24 Kazantzis G. The measurement of tremor in the early diagnosis of chronic mercurialism. Working paper to the symposium on maximum allowable concentration values. Stockholm, November 1968. Cited by Friberg L. Report of an international committee: maximum allowable concentration of mercury compounds. Arch Environ Health 1969;19:891-905.

25 Verberk MM, Salle HJA, Kemper CH. Tremor in workers with low exposure to metallic mercury. Am Ind Hyg Assoc J 1986;47:559-62.

26 Dietz V, Allum J, Freund H. Differences between normals, myopathies and polyneuropathies observed in physiological tremor power spectra. Third international congress of electrophysiology and kinesiology abstracts. Pavia, 1976:49-52.

27 Freund HJ, Hefter H, Homberg V, Reiners K. Determinants of tremor rate. In: Findley LJ, Capildeo R, eds. Movement disorders: tremor. New York: Oxford University Press, 1984.

28 Schuckmann F. Study of preclinical changes in workers exposed to inorganic mercury in chloralkali plants. Int Arch Occup Environ Health 1979;44:193-200.

29 Gerstner HB, Huff JE. Clinical toxicology of mercury. J Toxicol Environ Health 1977;2:491-526.

30 Berlin M. Mercury. In: Friberg L, ed. Handbook on the toxicology of metals. Amsterdam: Elsevier, 1979.

31 Takahata N. Accumulation of mercury in the brains of two autopsy cases with chronic inorganic mercury poisoning. Folia Psychiatry Neurology Japan 1970;24:59-69.

32 Iyer K, Goodgold J, Eberstein A, Berg P. Mercury poisoning in a dentist. Arch Neurol 1976;33:788-90.

33 Jacobs M, Ladd A, Goldwater L. Absorption and excretion of mercury in man. Arch Environ Health 1964;9:454-63.

34 Lamm O, Pratt H. Subclinical effects of exposure to inorganic mercury revealed by somatosensory-evoked potentials. Eur Neurol 1985;24:237-43.

35 Roels $\mathrm{H}$, Lauwerys $\mathrm{R}$, Buchet $\mathrm{J}$, et al. Comparison of renal function and psychomotor performance in workers exposed to elemental mercury. Int Arch Occup Environ Health 1982; 50:77-93.

36 Rosenman KD, Valcuikas JA, Glickman L, Meyers BR, Cinotti A. Sensitive indicators of inorganic mercury toxicity. Arch Environ Health 1986;41:208-15.

37 Stopford W, Bundy S, Goldwater L. Microenvironmental exposure to mercury vapor. Am Ind Hyg Assoc J 1978; 39:378-84.

38 Hanninen $\mathrm{H}$. Twenty-five years of behavioral toxicology within occupational medicine: a personal account. Am J Ind Med 1985;7:19-30.

$39 \mathrm{He}$ F, Zhang S. Prognosis of chronic mercury poisoning in mercury refinery workers (abstract). Scand J Work Environ Health 1984;10:125.

40 Kark RA, Poskanzer DC, Bullock JD, Boylen G. Mercury poisoning and its treatment with $\mathrm{N}$-acetyl-D,L-penicillamine. New England Journal of Medicine 1971;285:10-6.

Accepted 14 May 1990 